\title{
Economic Valuation of Lippia adoensis, implication for Access and Benefit Sharing agreement in Sidama and WestArsi Zones, SNNPR and Oromia Regions, Ethiopia
}

\begin{abstract}
Biodiversity has major economic value. Most of these values are often not captured by the market. Hence, the potential of biodiversity is often underestimated. Such an underestimation is considered as one of the factors for rapid depletion of biodiversity and loss of habitats and species. Valuation of bio-resources would facilitate in identifying the real value of genetic resources and obtaining a reasonably better share of the overall benefits of genetic materials to the local communities, who are involved in its management. Accordingly, the Economic Valuation of Lippia adoensis was conducted implication for ABS. The result of this study identified the direct and indirect use values of Lippia adoensis. Majority of the respondents (98.33\%) were willing to pay for use values of Lippia adoensis. Moreover, (80.8\%) of the respondents were willingness to pay for Conservation of Lippia adoensis. Furthermore, 95(79.2\%) of the respondents were willingness to pay for non-use value of Lippia adoensis in the study areas. The cumulative estimates of willingness to pay for use of values Lippia adoensis were 30,437.50 birr with an average annual willingness to pay of $253.64 \pm 275.63$ birr for Lippia adoensis. The maximum willingness to pay was 1000 birr while the minimum WTP was 125 birr with range 875 birr. The value of $\mathrm{R}^{2}$ for linear function (model) was 0.541 , semi $\log \mathrm{R}^{2}=0.452$ and double $\log \mathrm{R}^{2}=0.291$.From the given result the linear regression function $\left(\mathrm{R}^{2}=0.541\right)$ the one with the best performance. The $\mathrm{R}^{2}=0.541$ or $54.1 \%$, this means that the dependent variable can be explained by the independent variable. In this study, household size (Sig.0.000), income level (Sig.0.000), number of Lippia adoensis (Sig.0.044) and distance of the market (Sig. 0.051) of the respondents made a unique and statistically significant, contribution to the prediction of willingness to pay for Lippia adoensis. Of the nine variables, household size of the responders makes the largest unique contribution (beta $=0.490$ ), followed by income level of the respondents (beta -0.396). Therefore, because of its prospect for the production of many preservative, spices, aromatherapy, medicine and pharmaceuticals industry, bio prospecting companies require to access the genetic resources following the Ethiopian legislation of Access and Benefit Sharing.
\end{abstract}

Keywords: Lippia adoensis, valuation, willingness to pay, dependent and independent variable
Volume 4 Issue 5 - 2019

\author{
Amare Seifu, Tesfaye Bekele, Manaye \\ Misganawand, Ashenafi Ayenew \\ Ethiopian Biodiversity Institute, Genetic Resources Access and \\ Benefit Sharing Directorate, Ethiopia
}

Correspondence: Amare Seifu, Ethiopian Biodiversity Institute, Genetic Resources Access and Benefit Sharing Directorate, Ethiopia,Tel +251916595709, Email ameseifu21@gmail.com

Received: October 09, 2019 | Published: October 30, 2019
Abbreviations: WTP, willingness to pay; ABS, access and benefit sharing; ESs, ecosystem services; TVE, total economic valuation; TEV, total economic value; $\mathrm{UV}$, use value; NUV, non-use value; DUV, direct use values; IUV, indirect use values; OV, option values

\section{Introduction}

Biodiversity has major economic value that is both implied and overt. Most of these values are often not captured by the market .Biodiversity valuation normally entails measuring the economic value of 'biological resources', not the intrinsic value of biodiversity. Instead, valuation typically focuses on the economic values of the goods and services generated by biodiversity resources and/or functions-the so-called ecosystem services. ${ }^{1-3}$ Although all people depend on nature for their well-being, the benefits of nature are often neglected in policies; moreover, losses in natural capital have direct economic consequences that are often underestimated. The benefits deriving from ESs and the costs of the degradation and loss of ecosystems and biodiversity are incur incurred on the ground but may be largely unnoticed at a larger scale. ${ }^{4}$ Valuation can be defined as the process of attributing a certain economic or non-economic value to something. It aims to measure, in monetary terms, people's preferences for the benefits they obtain from (for example) ESs. Valuing ESs is part of informing political decision making: it can help in balancing the trade-offs in resource allocation when designing projects or investments and choosing among alternative land uses. ${ }^{5}$

The framework commonly used for valuing natural resources is known as the Total Economic Value (TEV). This comprises use values (direct, indirect and option value) and non-use values. ${ }^{4}$ Conceptually, TEV of an environmental resource (ecosystem) consists of its Use Value (UV) and Non-Use Value (NUV). A use value is a value (in the form of commodities and services) arising from an actual use made of a given resource. ${ }^{5,6}$ This might be the use of a forest for timber and non-timber forest products, or of a wetland for recreation or fishing. 
Use values are further divided into Direct Use Values (DUV), which refer to actual uses such as fishing, timber extraction and others; Indirect Use Values (IUV), which refer to the benefits deriving from ecosystem functions such as a forest's function in protecting the watershed; and Option Values (OV), which is a value approximating an individual's willingness to pay to safeguard an asset for the option of using it at a future date, like an insurance value. ${ }^{7}$

In the Access and Benefit Sharing perspective, the direct use value of the ecosystem or biodiversity, particularly the goods that have market potential and business scope, is significant. In brief, from an ABS perspective, use value - particularly direct use values - in the form of goods/resources which are tangible or visible is significant and should be considered as paramount in working on valuation related processes rather than using the tradition valuation methodology. These resources, which include different genetic materials, are extracted by local communities with the help of their unique traditional knowledge on their use and sold to prospectors at low or negligible prices. Since there are no proper markets for such resources at its collection point, the existing price for the product is not revealing its actual value. Actual value may be more than the existing market price. ${ }^{8,9}$

Providers of biological/genetic resources have limited knowledge and information about both the "price" and "value" of a product. On the contrary, the users of bio-resources (prospectors) have better knowledge about their potential value than the providers. However, the providers (local communities) are often exploited since they are little aware of about the potential of resources for value addition, product development and subsequent commercialization. Thus, the negotiations on determining the benefit sharing element could be potentially compromised where the provider is unaware of the potential use and value while the user has specific use and potential market in mind.

In this context, the valuation of biodiversity/ecosystem goods is a fundamental step towards determining the real value of bio-resources, and prepared the ABS provisions under Nagoya Protocol on ABS to capture the 'fair and equitable' provision of the ABS negotiations appropriately with full and informed participation of providers of the resources. Ethiopia is endowed with rich plant biodiversity and associated traditional plant genetic resources which make an environment for successful bio-prospecting. ${ }^{10}$ In this regards, Lippia adoensis (cultivated) is rich in linalol (as much as $80 \%$ ), which has many prospects for preservative, spices, aromatherapy, medicine and pharmaceuticals, which shows the ability of this resource for access and benefit sharing. ${ }^{11}$ Because of its prospect for the development of these products, bio prospecting companies require accessing the resources following the domestic legislation of ABS.

However, Lippia adoensis is one of the cultivated endemic plants which have not been properly valued..$^{12}$ The purpose of valuation is to establish what the weight of biodiversity conservation should be when the interest of the whole society is taken into account. Economic valuation helps authorities to make informed decision about the biodiversity conservation. Accordingly, Lippia adoensis is being widely used for preservative, as spices for butter preparation or flavor butter and other cultural food, traditional medicine and income generation. ${ }^{13}$ Though the Ethno-medicinal uses and chemical composition have been carried out on Lippia adoensis in Ethiopia, much has not been done on economic valuation. ${ }^{14,15}$ Proper understanding of the direct and indirect use values of this species in the study areas contributes to the conservation, sustainable utilization, and access and benefit sharing. ${ }^{16,17}$ Therefore, this study focused on the economic valuation of Lippia adoensis in Sidama and West Arsi Zones, SNNPR and Oromia Regions, Ethiopia and the implication for ABS agreement.

\section{Methodology}

\section{Description of the study areas}

Sidama Zone is a zone in the Southern Nations, Nationalities, and Peoples' Region (SNNPR) of Ethiopia. It is named for the Sidama people, whose homeland is in the zone. Sidama is bordered on the south by the Oromia Region, on the west by the Bilate River, which separates it from Wolayita zone, and on the north and east by the Oromia Region. Towns in Sidama include which includes Hawassa, the capital of Sidama and SNNPRS, Yirgalem and Wendo. West Arsi zone is one of the zones of the Oromia Region in Ethiopia which shares borderlines with the Regional State of Nations, Nationalities and People of Southern Ethiopia and borderlines with East Shewa and Bale (Figure 1)? ${ }^{18}$

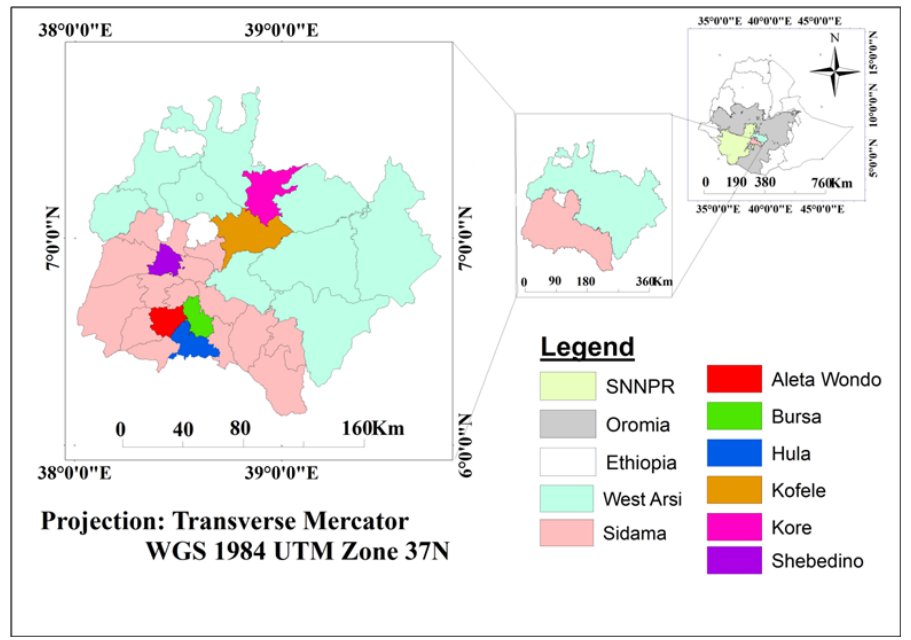

Figure I Administrative Map of the study areas.

Projection:Transverse Mercator WGS I984UTM Zone 37N 


\section{Sampling design/ techniques}

The study areas were selected based on the abundance of Lippia adoensis. Based on the recommendations of zonal agricultural office six potential Lippia adoensis growing districts were selected from Sidama and West Arsi Zones, four districts from Sidama (Bursa, Hula, Aleta Wondo and Shebedino) and two districts from West Arsi (Kofele and Koree) Zones. In addition, two Kebeles were selected from each district bringing the total number of sampled Kebeles to 12 where Lippia adoensis is abundantly found Guchi, Qabete, Shire kobolcha and Meja Yedel were selected from West Arsi. Qenqelcha, Hoba Gangawa, Bursa Qosercha, Chelbesa, Titira, Woto, Termesa and Fura from Sidam Zone were selected to conduct the study.

\section{Sample size determination}

Taking into consideration cost, labor and time, the researchers determined the sample size, using the formula:- $\mathrm{N}>50+8 \mathrm{~m}$ where $\mathrm{N}$ is sample size and $\mathrm{m}$ number of independent variables. ${ }^{19}$

Table I Factors selected to determine willingness to pay of Lippia adoensis

\section{Methods of data collection}

A reconnaissance survey was made to determine the initial bid of Lippia adoensis, to select the study districts and kebeles and to pre-test the questionnaires which were helped to make necessary modifications according to the prevailing local circumstances.

The main instrument of primary data collection was a structured and pretested questionnaire. Additional data was obtained from the agricultural office of the districts, from different books, journals and research articles. For this study both qualitative and quantitative data was collected from primary and secondary sources. Respondents were selected with the help of kebeles extension agents based on experiential ethno botanical knowledge of Lippia adoensis.

\section{Variables determining willingness to pay}

It was assumed that the explanatory variables/factors that determine willingness to pay of Lippia adoensis was: age, sex, income level, marital status, household size, size of land, distance from the market and education status following Adekunle and Agbaje (2011) (Table 1).

\begin{tabular}{|c|c|c|c|}
\hline S.No. & Variables & Descriptions & Remark \\
\hline I & Age & Age of the respondents & \\
\hline 2 & Sex & 0 : Female I : Male & \\
\hline 3 & Income level & 0 : Low I : Medium 2 : High & \\
\hline 4 & Marital status & 0: Married I:Unmarried 2: Divorce 3 :Widowed & \\
\hline 5 & Household size & Number of people in the given family & Independent variables \\
\hline 6 & Size of land & The size of land the respondents possess in hectare & \\
\hline 7 & Distance from the market & Distance of the market in which Lippia adoensis is sold & \\
\hline 8 & Education status & $\begin{array}{l}0: \text { Non educated I :Informal education 2:Primary education 3: } \\
\text { Secondary education } 4: \text { Higher education }\end{array}$ & \\
\hline 9 & $\begin{array}{l}\text { Number of individual } \\
\text { Lippia adoensis }\end{array}$ & $\begin{array}{l}\text { Number of individual Lippia adoensis present in at the } \\
\text { respondents land }\end{array}$ & \\
\hline \multicolumn{3}{|c|}{ Amount of money Willingness to pay for Lippia adoensis } & Dependent/ output variable \\
\hline
\end{tabular}

\section{Data analysis and interpretation}

The collected data was subjected to SPSS software version 21 and analyzed and interpreted using descriptive and inferential statistics. Regression Analysis was used to test models to predict outcomes of variables. The predictor (independent) variables can be either categorical or continuous, or a mix of both in the same model. An inferential method was used for detail analysis of the variables. The appropriate model for the nature of the dependent variable was served as an inferential model. Mean willingness to pay, standard deviation, confidence interval and the relationship between WTP and categorical variables was analyzed using descriptive statistics. The WTP bids were also regressed with various explanatory variables. The bid functions were arrived at using multiple linear regression analysis, starting from all the potential explanatory variables, removing the least significant one, re-estimating the model and so on until all remaining variables was significant at $95 \%$ level. ${ }^{5}$ The valuation function will be:

$$
\begin{aligned}
& \text { WTP }=\beta_{0}+\beta_{1} X_{1}+\beta_{2} X_{2}+\beta_{3} X_{3}+\beta_{4} X_{4}+\beta_{5} X_{5}--------\beta_{n} X_{n}+\beta_{n} X_{n}+e_{n} \\
& \text { WhereWTP }=\text { farmers willingness to pay for Lippia adoensis, } \beta_{0=}
\end{aligned}
$$

constant, $\beta_{1}-\beta_{n=}$ coefficients, $X_{1-} X_{n}=$ variables influencing WTP, $e_{n}=$ random error or in elaborated manner :-

$$
\mathrm{WTP}=\mathrm{f}\left(\mathrm{X}_{1}+\mathrm{X}_{2}+\mathrm{X}_{3}+\mathrm{X}_{4}+\mathrm{X}_{5}+\mathrm{X}_{6}+\mathrm{X}_{7}+\ldots \ldots \ldots . . \mathrm{X}_{\mathrm{n}}+\mathrm{e}\right)(1)
$$

Where WTP $=$ Willingness to pay, $\mathrm{X}_{1}=$ Age, $\mathrm{X}_{2}=$ Sex, $\mathrm{X}_{3}=$ Income level, $X_{4}=$ Marital status, $X_{5}=$ Household size, $X_{6}=$ Size of land in hectare, $\mathrm{X}_{7}=$ Distance from the market, $\mathrm{X}_{8}=$ Education status, $\mathrm{X}_{9}=$ number of individual Lippia adoensis, $\mathrm{e}=$ error term

Three functional forms was tried in order to choose the one with the best performance. (3)

$$
\begin{aligned}
& \text { Linear: WTP }=b_{0}+b_{1} X_{1}+b_{2} X_{2}+\ldots \ldots b_{7} X_{7}+E d(2) \\
& \text { Semi log: WTP }=L_{n} b_{0}+b_{1} L_{n} X_{1}+b_{2} L_{n} X_{2}+\ldots \ldots \ldots \ldots b_{7} L_{n} X_{7}+L_{n} E d
\end{aligned}
$$

Double Log: $\mathrm{L}_{\mathrm{n}} \mathrm{WTP}=\mathrm{L}_{\mathrm{n}} \mathrm{b}_{\mathrm{o}}+\mathrm{b}_{1} \mathrm{~L}_{\mathrm{n}} \mathrm{b}_{1} \mathrm{X}_{1}+\mathrm{b}_{2} \mathrm{~L}_{\mathrm{n}} \mathrm{X}_{2}+\mathrm{b}_{7} \mathrm{~L}_{\mathrm{n}} \mathrm{X}_{7}+\mathrm{L}_{\mathrm{n}} \mathrm{Ed}$ (4)

Where, $b_{o}=$ constant, $b_{1} b_{2} \ldots b_{7}=$ Regression coefficient for WTP $\mathrm{Ed}=$ Residual or error term, $\mathrm{L}_{\mathrm{n}}=$ Natural logarithm 


\section{Results and discussions}

\section{Demographic characteristics of the Respondents}

A total of 120 respondents, 64 female $(53.3 \%)$ and 56 male (46.7\%), were interviewed from February to April 2019. The age of respondents ranged between 20 and 72 years old with mean age of $37.9 \pm 11.99$ years, and range 52years. A majority of the respondents $112(93.3 \%)$ were married, $7(5.8 \%)$ were widowed and an insignificant number of the respondent was divorced. Among the respondents interviewed, $34(28.3 \%)$ were non-educated, $8(6.7 \%)$ had informal education, $54(45 \%)$ received primary education and the rest $(24,20 \%)$ were educated in secondary schools. Moreover, the income level of the respondents were medium, low and high $\{71$ (59.2\%), 35 (29.2\%) and $14(11.7 \%)\}$ respectively.

\section{Direct and indirect use values of Lippia adoensis}

The use value of Lippia adoensis consists of direct and indirect use values. The direct use values of this plant include use for spices, butter preparation or as flavor, traditional medicine, and food preservative etc. ${ }^{20}$ All of the respondents $(100 \%)$ reported the use of Lippia adoensis for spices, preservatives, providing good aroma for food, as spice for butter preparation and flavoring of food. Moreover, most of the respondents (59.2\%) reported using Lippia adoensis for traditional medicine (Table 2).

\section{a. The willingness to payof the respondents for Lippia adoensis}

A majority of the respondents $(119,98.33 \%)$ were willing to pay for use values of Lippia adoensis. According to the respondents reports, the main reasons of willing to pay for Lippia adoensis were due to its different use values such as using as spice, preservative, traditional medicine, etc... Moreover, 97(80.8\%) of the respondents were willing to pay for the conservation of Lippia adoensis (willing to pay the minimum amount of compensation required to maintain its original utility level), whereas $23(19.2 \%)$ of the respondents were not willing to pay for the conservation of Lippia adoensis in the study areas. Furthermore, 95(79.2\%) of the respondents were willing to pay for non-use value, of Lippia adoensis (willing to pay for bequest value/inter-generational equity concern/and altruist/intra-generational equity concern) where as $25(20.8 \%)$ of the respondents were not willing to pay for the non-use value of Lippia adoensis in the study areas (Table 3).

Table 2 Respondents' statements on the use values of Lippia adoensia in the study areas

\begin{tabular}{lllll}
\hline \multirow{2}{*}{ The uses of Lippia adoensis } & \multicolumn{3}{c}{ Yes } & No \\
\cline { 2 - 5 } & Frequency & Percentage (\%) & Frequency & Percentage (\%) \\
\hline Spices and flavoring of food & 102 & $85 \%$ & 18 & $15 \%$ \\
Preservative \& providing good smell for food & 120 & $100 \%$ & - & --- \\
Traditional medicine & 71 & $59.20 \%$ & 49 & $40.80 \%$ \\
Providing good smell to the surrounding & 119 & $99.20 \%$ & 1 & 0.83 \\
Income source & 115 & $95.80 \%$ & 5 & $4.20 \%$ \\
\hline
\end{tabular}

Table 3 Respondents statement on willingness to payfor Lippia adoensis

\begin{tabular}{|c|c|c|c|c|}
\hline Category & & Yes & No & Total \\
\hline \multirow{2}{*}{ Willingness to pay for use values } & Frequency & 118 & 2 & 120 \\
\hline & Percent & 98.3 & 1.7 & 100 \\
\hline \multirow{2}{*}{ Willingness to pay for conservation activities } & Frequency & 97 & 23 & 120 \\
\hline & Percent & 80.8 & 19.2 & 100 \\
\hline \multirow{2}{*}{$\begin{array}{l}\text { Non-use values(Bequest value/Inter-generational equity concern/ and Altruist/Intra-generational equity } \\
\text { concern) }\end{array}$} & Frequency & 95 & 25 & 120 \\
\hline & Percent & 79.2 & 20.8 & 100 \\
\hline
\end{tabular}

b. The mean willingness to pay for use values of Lippia adoensis across different socio -economic classes

The annual mean willingness to pay of the respondents across different socioeconomic classes (age, sex, marital and educational status and income level) for use values of Lippia adoensis was investigated.- In the age-related socio-economic class, the mean willingness to pay were $245.83,267.23,255.77$ and 244.81 birr within the ranges of 15-24, 25-44, 45-64 and 45-80 age classes respectively. There was a very little variation in the mean willingness to pay for use values of Lippia adoensis across different age classes. This result suggests that the willingness to pay for use values of Lippia adoensis did not depend on ages of the respondents.

As to gender class, the mean willingness to pay of females respondents (275.74birr) was somewhat greater than males respondents (230.08birr). Regarding to the impact of marital status of the respondents on willingness to pay for Lippia adoensis, mean willingness to pay by married, unmarried and divorce respondents were $257.23,234.04$ and 268.96 birr respectively. This would suggest that willingness to pay of Lippia adoensis does not depend on marital status of the respondents. This could be because all married, widowed and divorced respondents had almost similar views on the use values of Lippia adoensis.

As to the educational status of the respondents, the highest mean willingness to pay was recorded with non-educated respondents (292.18birr), followed by respondents with informal (262.62birr) and primary level education (237.19birr) however, the minimum average willingness to pay was recorded at secondary school respondents (213.66birr). This indicated as education levels increase, the average willingness to pay of the respondents' decrease. This could be because 
as the educational level of the respondents increase, the consciousness to traditional use value of the genetic resource decrease which is directly related to the current modernization.

Regarding to the income level of the respondents, the highest mean willingness to pay was recorded at high income level (296.26birr) followed by respondent with medium income level (257.57birr) and the lowest mean willingness to pay was recorded at low income level of the respondents (206.41birr).This indicated that as the income level of the respondents increases the mean willingness to pay also increases. This could be due to as the income level of the respondents increase, they are stressed-free to pay for the use values of the genetic resources but as their income level decrease, they become hesitant to pay the use value of the given genetic resources (Table 4).

Table 4 Mean Willingness to Pay for use values of Lippia adoensis per year across Different Socio -Economic Classes

\begin{tabular}{|c|c|c|c|c|c|}
\hline \multirow[t]{2}{*}{ No. } & \multirow[t]{2}{*}{ Socio-economic classes } & \multicolumn{2}{|c|}{$\begin{array}{l}\text { Number of respondents in each socio-economic } \\
\text { classes }\end{array}$} & \multirow{2}{*}{$\begin{array}{l}\text { Mean willingness to pay } \\
\text { in Birr per year }\end{array}$} & \multirow[t]{2}{*}{ Total } \\
\hline & & Willing to pay & Not willing to pay & & \\
\hline \multirow{5}{*}{ I } & Age & & & & \\
\hline & $15 \_24$ & 8 & - & 245.83 & \multirow{4}{*}{120} \\
\hline & $25 \_44$ & 79 & I & 267.23 & \\
\hline & $45 \_64$ & 27 & 1 & 255.77 & \\
\hline & $65 \_80$ & 4 & - & 244.81 & \\
\hline \multirow{3}{*}{2} & Sex & & & & \multirow{3}{*}{120} \\
\hline & Female & 63 & I & 275.74 & \\
\hline & Male & 55 & 1 & 231.09 & \\
\hline \multirow{4}{*}{3} & Marital Status & & & & \\
\hline & Married & 110 & 2 & 257.23 & \multirow{3}{*}{120} \\
\hline & Divorce & I & - & 268.96 & \\
\hline & Widowed & 7 & - & 234.04 & \\
\hline \multirow{5}{*}{4} & Educational Status & & & & \multirow{5}{*}{120} \\
\hline & Non-Educated & 33 & I & 292.18 & \\
\hline & Informal Education & 7 & 1 & 262.62 & \\
\hline & Primary Education & 54 & - & 237.19 & \\
\hline & Secondary Education & 24 & - & 213.66 & \\
\hline \multirow{4}{*}{5} & Income Level & & & & \multirow{4}{*}{120} \\
\hline & Low & 35 & - & 206.41 & \\
\hline & Medium & 71 & 2 & 257.57 & \\
\hline & High & 14 & - & 296.26 & \\
\hline
\end{tabular}

c. Average and cumulative estimates of WTP for use and non-use values of Lippia adoensis

The cumulative estimates of WTP for use of values Lippia adoensis were 30,437.50 birr with an average annual willingness to pay of $253.64 \pm 275.63$ birr. The maximum WTP was 1000 birr while the minimum WTP for Lippia adoensis was 125 birr with range 875birr Concerning to the cumulative estimates of willingness to pay for non-use values of Lippia adoensis was 23,437.70birr with an average annual willingness to pay of $195.30 \pm 169.65$ birr. The maximum WTP to pay was 500birr while the minimum WTP was 125 birr with range 375 birr. The most frequent willingness to pay was $250 \mathrm{birr}$.

The mean willingness to pay for conservation activities of Lippia adoensis was $197.40 \pm 168.10$ with cumulative estimates of willingness to pay of 23,687.50birr. The maximum willingness to pay was 500 birr while the minimum WTP was 125 birr with a range of 375birr and a mode of 250birr. The largest cumulative estimates of willingness to pay for use values were 39,658 .80birr followed by 23,687.50birr WTP for conservation activities and 23,437.70birr for non-use values).

\section{d. Results of multiple regression analysis}

The independent variables show at least some relationship with the dependent variable. In this study, household size (0.566) and income level $(-0.562)$ of the respondents correlate with amount of money the respondents were willing to pay for Lippia adoensis. This was followed by the number of individual Lippia adoensis plants present on respondents land $(0.194)$, the size of land $(0.147)$, educational status (-0.099),distance of the market from respondents home (0.081), age $(0.064)$, marital status $(0.058)$ and gender $(-0.001)$ respectively. The correlation between each of the independent variables is not well correlated. If two variables with a bivariate correlation of 0.7 or more occur in the same analysis, it is probably not necessary to include them in the given analysis. In this situation, one may need to consider omitting one of the variables or forming a composite variable from the scores of the two highly correlated variables. ${ }^{21}$ The correlation of the independent variable income level with household size (-0.302), income level /marital status (0.141), income level /educational status $(-0.073)$ and income level/size of land $(-0.121)$ etc... Generally, in the 
current study, the correlation of each of the independent variable to each other is less than 0.7; therefore all variables were retained in the analysis.

\section{i. Multicollinearity}

Multicollinearity exists when the independent variables are highly correlated ( $\mathrm{r}=0.9$ and above); subsequently, multicollinearity did not exist since the independent variables were not highly correlated. The existence of multicollinearity can also be determined by tolerance, an indicator of how much of the variability of the specified independent variables are not explained by the other independent variables, and is calculated as $1-\mathrm{R}^{2}$. In this study, the tolerance values were large, ranging between 0.773 and 0.918 , thus indicating multicollinearity did not exist. The variance inflation factor (VIF), which is the inverse of tolerance, ranged between 1.089 and 1.293 which is less than 10 , indicating-multicollinearity did not exist (Table 5).

Table 5 Multiple regressions output (Coefficients' Confidence Intervals for B, Correlations and, Collinearity statistics

\begin{tabular}{|c|c|c|c|c|c|c|c|c|c|c|c|c|}
\hline \multirow{2}{*}{ Model } & \multicolumn{2}{|c|}{$\begin{array}{l}\text { Un-standardized } \\
\text { coefficients }\end{array}$} & \multirow{2}{*}{$\begin{array}{l}\text { Standardized } \\
\text { coefficients } \\
\text { Beta }\end{array}$} & \multirow{2}{*}{$\mathbf{t}$} & \multirow{2}{*}{ Sig. } & \multicolumn{2}{|c|}{$\begin{array}{l}95.0 \% \text { Confidence } \\
\text { interval for B }\end{array}$} & \multicolumn{2}{|c|}{ Correlations } & \multirow{2}{*}{ Part } & \multicolumn{2}{|c|}{ Collinearity statistics } \\
\hline & B & $\begin{array}{l}\text { Std. } \\
\text { Error }\end{array}$ & & & & $\begin{array}{l}\text { Lower } \\
\text { bound }\end{array}$ & $\begin{array}{l}\text { Upper } \\
\text { bound }\end{array}$ & $\begin{array}{l}\text { Zero- } \\
\text { order }\end{array}$ & Partial & & Tolerance & VIF \\
\hline (Constant) & 346.552 & 74.872 & & 4.629 & 0 & 198.17 & 494.9 & & & & & \\
\hline Age of the responders & -1.682 & 1.216 & -0.098 & -1.384 & 0.169 & -4.091 & 0.727 & -0.064 & -0.131 & -0.089 & 0.837 & 1.195 \\
\hline Household size & 33.623 & 5.037 & 0.49 & 6.675 & 0 & 23.64 & 43.606 & 0.566 & 0.537 & 0.431 & 0.773 & 1.293 \\
\hline Size of land in hectares & 2.692 & 15.333 & 0.012 & 0.176 & 0.861 & -27.694 & 33.078 & 0.147 & 0.017 & 0.011 & 0.891 & 1.122 \\
\hline Distance of the market & $-|0.5| 1$ & 5.325 & -0.137 & -1.974 & 0.051 & -21.064 & 0.041 & -0.081 & -0.185 & -0.127 & 0.869 & 1.151 \\
\hline I & & & & & & & & & & & & \\
\hline Number of Lippia adoensis & 2.735 & 1.341 & 0.142 & 2.04 & 0.044 & 0.078 & 5.393 & 0.194 & 0.191 & 0.132 & 0.863 & 1.159 \\
\hline $\operatorname{Sex}(0)$ & -0.989 & 29.491 & -0.002 & -0.034 & 0.973 & -59.434 & 57.455 & 0.001 & -0.003 & -0.002 & 0.814 & 1.228 \\
\hline Educational status $(0)$ & 41.905 & 32.65 & 0.092 & 1.283 & 0.202 & -22.8 & 106.61 & -0.099 & 0.121 & 0.083 & 0.814 & 1.228 \\
\hline Income level(0) & -197.484 & 36.392 & -0.396 & -5.427 & 0 & -269.605 & 125.363 & -0.562 & -0.46 & -0.35 & 0.784 & 1.275 \\
\hline Marital status(0) & -55.57 & 55.547 & -0.067 & -1 & 0.319 & $165.65 \mid$ & 54.512 & -0.058 & -0.095 & -0.065 & 0.918 & 1.089 \\
\hline
\end{tabular}

\section{ii. Evaluating the model}

The $\mathrm{R}^{2}$ value indicates how much of the dependent variable (WTP) can be explained by the independent variables (age, sex, marital status, educational status, household size, size of land, income level, number of individual Lippia adoensis plants and distance from the market).There are three functions which were attempted to choose the one with the best performance (the dependent variable explained best by the independent variables). Generally the function for willingness to pay is $\mathrm{WTP}=\mathrm{f}(\mathrm{X} 1+\mathrm{X} 2+\mathrm{X} 3+\mathrm{X} 4+\mathrm{X} 5+\mathrm{X} 6+\mathrm{X} 7+$ (where WTP $=$ Willingness to pay, X1 = age, X2 = sex, X3 =marital status, $\mathrm{X} 4=$ educational level, $\mathrm{X} 5=$ household size, $\mathrm{X} 6=$ size of land, $\mathrm{X} 7=$ income level, $\mathrm{X} 8=$ number of individual Lippia adoensis plants, $\mathrm{X} 9=$ distance from the market, and $\mathrm{e}=$ error term.

In this study, the value of $\mathrm{R}^{2}$ for the linear model was 0.541 , semi $\log$ model $\mathrm{R}^{2}=0.452$ and double $\log$ model $\mathrm{R}^{2}=0.291$. Based on $\mathrm{R}^{2}$, the linear regression model performed the best. The $\mathrm{R}^{2}$ value indicates that the independent variables explained $54.1 \%$ of the variance in WTP (Table 6). 
Table 6 Regression results for explanatory variables that determine WTP of Lippia adoensis

\begin{tabular}{|c|c|c|c|c|c|c|c|c|c|c|c|c|c|}
\hline Regression & Bo & $\mathbf{X I}$ & $\mathbf{X 2}$ & $\begin{array}{l}\text { Marital } \\
\text { Status(0) }\end{array}$ & $\begin{array}{l}\text { Education } \\
\text { level(0) }\end{array}$ & $\begin{array}{l}\text { Household } \\
\text { size }\end{array}$ & $\begin{array}{l}\text { X6 Size } \\
\text { of land in } \\
\text { hectare }\end{array}$ & $\begin{array}{l}\text { Income } \\
\text { level(0) }\end{array}$ & $\begin{array}{l}\text { X8 } \\
\text { Number } \\
\text { of Lippia } \\
\text { adoensis }\end{array}$ & $\begin{array}{l}\text { X9 } \\
\text { Distance } \\
\text { from the } \\
\text { market }\end{array}$ & $\mathbf{R 2}$ & Adj. & Sig. \\
\hline Linear & $\begin{array}{l}346.552 \\
-74.872\end{array}$ & $\begin{array}{l}-1.682 \\
-1.216\end{array}$ & $\begin{array}{l}-.989 \\
(29.491)\end{array}$ & $\begin{array}{l}-55.570 \\
(55.547)\end{array}$ & $41.905(32.650)$ & $\begin{array}{l}33.623 \\
(5.037)\end{array}$ & $\begin{array}{l}2.692 \\
(15.333)\end{array}$ & $\begin{array}{l}-197.484 \\
(36.392)\end{array}$ & $\begin{array}{l}2.735 \\
-1.341\end{array}$ & $\begin{array}{l}-10.511 \\
-5.325\end{array}$ & 0.541 & 0.504 & 14.413 \\
\hline Semi-Log & $\begin{array}{l}198.049 \\
(205.284)\end{array}$ & $\begin{array}{l}-35.385 \\
(53.076)\end{array}$ & $\begin{array}{l}-11.275 \\
(32.436)\end{array}$ & $\begin{array}{l}51.015 \\
(60.931)\end{array}$ & $-44.878(35.906)$ & $\begin{array}{l}114.548 \\
(27.177)\end{array}$ & $\begin{array}{l}13.269 \\
(22.093)\end{array}$ & $\begin{array}{l}213.567 \\
-40.785\end{array}$ & $\begin{array}{l}28.695 \\
-16.854\end{array}$ & $\begin{array}{l}-34.799 \\
-24.71\end{array}$ & 0.452 & 0.407 & 10.067 \\
\hline Double-Log & $\begin{array}{l}4.901 \\
(0.608)\end{array}$ & $\begin{array}{l}0.006 \\
(0.162)\end{array}$ & $\begin{array}{l}-0.064(0 . \\
080)\end{array}$ & $\begin{array}{l}0.203 \\
-0.151\end{array}$ & $\begin{array}{l}-0.003 \\
-0.089\end{array}$ & $\begin{array}{l}-0.415 \\
-0.076\end{array}$ & $\begin{array}{l}0.022 \\
(0.069)\end{array}$ & $\begin{array}{l}0.799 \\
-0.101\end{array}$ & $\begin{array}{l}0.15 \\
-0.05\end{array}$ & $\begin{array}{l}-0.011 \\
-0.076\end{array}$ & 0.291 & 0.26 & 9.376 \\
\hline
\end{tabular}

From the three functional forms that were tried in order to choose the one with the best performance, linear regression function has the best having the highest coefficient of determination $\left(\mathrm{R}^{2}\right)$ of $54.1 \%$ which intern helped to identify the best explanatory variables that determine WTP of Lippia adoensis (Table 6). The respondents' household size (sig.0.000), income (sig. 0.000), number of individuals Lippia adoensis plant (sig.0.044) and distance of the market (sig. 0.051 ) had significant influence on the amount of the respondents willing to pay for Lippia adoensis. This is an indication that WTP for Lippia adoensis might be determined through the household size, income level, number of individuals Lippia adoensis plant present at the respondents land and distance of the market from the respondents' home. In constructing a regression equation, it would be used the unstandardized coefficient values in Table 5 above.

\section{iii. Evaluating each of the independent variables}

In comparing the contribution of each independent variable, the beta values were used by finding the largest beta value (ignoring any negative signs out the front). In this study, the largest beta coefficient was 0.490 for household size of the responders. This means that this variable made the strongest unique contribution in explaining the dependent variable, followed by income level of the respondents (-0.396), number of Lippia adoensis (0.142) and distance of the market(-0.136).The Beta values for the other variables were lower, indicating that they made less unique contribution to the dependent variable. If the significance value is less than 0.05 , the variable is making a significant unique contribution to the prediction of the dependent variable. If greater than 0.05 , it can be concluded that the variable is not making a significant unique contribution to the prediction of the dependent variable. This may be due to overlap with other independent variables in the model. In this study, household size (Sig.0.000), income level (Sig.0.000), number of Lippia adoensis plants (Sig.0.044) and distance to the market (Sig. 0.051) of the respondents made a unique and statistically significant, contribution to the prediction of WTP for Lippia adoensis.

In the coefficients table, the other potentially useful information is the Part correlation coefficient which is referred as semi partial correlation coefficients..$^{21}$ The square of this value is an indication of the contribution of that variable to the total R square. In other words, it indicates how much of the total variance in the dependent variable is uniquely explained by that variable and how much $\mathrm{R}$ square would drop if it wasn't included in study model. In this study, the age, sex $(0)$, marital status (0), educational status (0), household size, size of land in hectares, income level (0), number of individuals Lippia adoensis and distance of the market had a part correlation co-efficient of $-0.131,-0.002,-0.065,0.083,0.431,0.011,-0.350,0.132$ and -0.127 respectively. The square of these values were $0.0172,0.000004,0.0042$, $0.0069,0.1858,0.00012,0.1225,0.01742$ and 0.01613 respectively, indicating that each of the independent variable in this study (Age, Sex (0), marital status (0), educational status (0), household size, size of land in hectares, income level (0), number of individuals Lippia adoensis and distance of the market) uniquely explained $1.72 \%, 0.0004 \%, 0.42 \%, 0.69 \%, 18.58 \%, 0.012 \%, 12.25 \%, 1.742 \%$ and $1.613 \%$ of the variance in the total willingness to pay for Lippia adoensis respectively (Table 5).

The total $\mathrm{R}$ square value for the model (in this study, 0.541 , or $54.1 \%$ explained variance) did not equal all the squared part correlation values added up $(1.72 \%+0.0004 \%+0.42 \%+0.69 \%+18.58 \%+$ $0.012 \%+12.25 \%+1.742 \%+1.613 \%=37.03)$. This is because the part correlation values represent only the unique contribution of each variable, with any overlap or shared variance removed. The total $R$ square value $(54.1 \%)$, however, includes the unique variance explained by each variable and also that shared. However, in this study, the nine independent variables were not strongly correlated with each other's which were between, $\mathrm{r}=-0.302$ income level/Household size and $\mathrm{r}=$ -0.003 Number of Lippia adoensis/Marital status as shown in the coefficient Table 5; therefore, there was a small difference between all the squared part correlation values added up $(37.03 \%)$ and the total $\mathrm{R}$ square value of the model (54.1\%)

Finally, the model, which includes Age, Sex (0), Marital status (0), Educational status (0), Household size, Size of land in hectares, Income level (0), number of individuals Lippia adoensis and distance of the market, explained $54.1 \%$ of the variance in willingness to pay for Lippia adoensis. Of the nine variables, household size of the responders make the largest unique contribution (beta $=0.490)$, followed by income level of the respondents (beta -0.396). ${ }^{22}$

\section{Conclusion and recommendation}

Valuation of genetic resources help to identify the real value of the resources and obtaining a reasonably better share of the overall benefits of it related economic activities to the local communities, who are involved in its management. Accordingly, the Economic Valuation of Lippia adoensis was conducted implication for Access and Benefit Sharing Agreement. The result of this study identified the direct and indirect use values of Lippia adoensis (Spices, food flavoring, as 
preservative, traditional medicine, income source, provide good smell to the surrounding, increase soil fertility and honeybee forage).

Majority of the respondents119 (98.33\%) were willing to pay for use values of Lippia adoensis. Moreover, 97(80.8\%) of the respondents were willingness to pay for Conservation of Lippia adoensis. Furthermore, 95(79.2\%) of the respondents were willingness to pay for non-use value of Lippia adoensis (willing to pay for Bequest value/ Inter-generational equity concern/and Altruist/Intra-generational equity concern) in the study areas. The cumulative estimates of willingness to pay for use of values Lippia adoensis were 30,437.50 birr with an average annual willingness to pay of $253.64 \pm 275.63$ birr for Lippia adoensis. The maximum willingness to pay was 1000 birr while the minimum WTP for Lippia adoensis was 125 birr with range $875 \mathrm{birr}$. The annual mean willingness to pay of the respondents across different socioeconomic classes (age, sex, marital and educational status and income level) for use values of Lippia adoensis had been also investigated. Accordingly, the highest mean willingness to pay was recorded in the high income socioeconomic class (296.26birr) and the lowest mean willingness to pay was recorded at low income status of the respondents (206.41 birr)

In this study, the value of $\mathrm{R}^{2}$ for linear function (model) was 0.541 , semi $\log R^{2}=0.452$ and double $\log R^{2}=0.291$. From the given result the linear regression function $\left(\mathrm{R}^{2}=0.541\right)$ the one with the best performance(the dependent variable explained best by the independent variables). The $\mathrm{R}^{2}=0.541$, this means that the model which includes (Age, Sex, Marital status, Educational status, Household size, Size of land in hectares, Income level, number of individual Lippia adoensis and distance from the market) explained $54.1 \%$ of the variance in amount of money willing to pay for Lippia adoensis or, $\mathrm{R}^{2}=0.541$ or $54.1 \%$ of the dependent variable can be explained by the independent variable.

In this study, household size (Sig.0.000), income level (Sig.0.000), number of Lippia adoensis (Sig.0.044) and distance of the market (Sig. 0.051) of the respondents made a unique and statistically significant, contribution to the prediction of willingness to pay for Lippia adoensis. Of the nine variables, household size of the responders makes the largest unique contribution (beta $=0.490$ ), followed by income level of the respondents (beta -0.396). Consequently, because of its prospect for the production of preservative, aromatherapy, cosmetics, medicine and pharmaceuticals, bio prospecting companies require accessing the resources following the domestic legislation of ABS.

\section{Acknowledgments}

The people of Sidama and West Arsi Zones, SNNPR and Oromia Regions, Ethiopia who gave us information are gratefully acknowledged. We are grateful to Ethiopian Biodiversity Institute (EBI) for financial support during fieldwork. We are also grateful to Agricultural workers in Hula,Aleta Wondo,Shebedino,Kofele and Koree districts for their translation Afan Oromo and Sidamgna language and kind assistance during the fieldwork.

\section{Funding}

None.

\section{Conflicts of interest}

The authors declared that there no conflicts of interest.

\section{References}

1. Convention on Biological Diversity. An exploration of tools and methodologies for valuation of biodiversity and biodiversity resources and functions. technical series no. 28, Montreal, Canada; 2007. 71 p.

2. Moran D, Bann C. The valuation of biological diversity for National biodiversity action plans and strategies: a guide for trainers. Prepared for the United Nations Environment Programme, Physica-VerlagHeidelberg, Pearce; 2000.

3. Nijkamp P. Economic valuation of biodiversity: A comparative study. Ecological Economics. 2008;67(2):217-231.

4. TEEB. The economics of ecosystems and biodiversity: TEEB for local and regional policy makers. United Nations Environment Programme (UNEP); 2010.

5. Horton B, Colarullo G, Bateman IJ, et al. Evaluating non user willingness to pay for a large scale conservation program in Amazonia: a UK/Italian contingent valuation study. Environmental conservation. 2003;30(2):139-146.

6. Millennium Ecosystem Assessment-MEA. Ecosystem and human wellbeing: a framework for assessment. Millennium Ecosystem Assessment Series, Island Press; 2003.

7. Masiero M, Pettenella D, Boscolo M, et al. Valuing forest ecosystem services a training manual for planners and project developers. Rome, Italy: FAO; 2019.

8. Pearce D, Moran D. The economic value of biodiversity. London: Earthscan Publication; 1994.

9. Anil M. the role of economic rent and its valuation in the context of access to genetic resources and fair and equitable sharing of the benefits arising out of their utilization. Presentation in Adhoc Open-ended Working Group on ABS of CBD; 2008.

10. Nelliyat P, Pisupati P. Economic valuation of bio-resources for access and benefit sharing. Chennai, India: National Biodiversity Authority; 2003.

11. Gemeda N, Woldeamanuel Y, Asrat D, et al. Assessment of Lippia adoensis hochst. var. koseret, rosmarinus officinalis 1 and ruta chalepensis 1. essential oils as a potential source of fungitoxic and mycosporicidal activity against toxigenic aspergillus species. Pharmacology on Linevol. 2015;2:85-94.

12. Ermias Dagne. Natural Database for Africa (NAD). Addis Ababa, Ethiopia; 2009.

13. Gemechu AB, Abdella GD, Dessalegn E. AntimicrobialActivity of Lippia adoensis var. koseret Against Human Pathogenic Bacteria and Fungi. American Journal of Clinical and Experimental Medicine. 2015;3(3):118-123.

14. Jigam AA, Akanya HO, Ogbadoyi EO, et al. In vivo anti plasmodial, analgesic and anti-inflammatory activities of the leaf extract of Lippia multiflora mold. J Med Plants Res. 2009;3(3):148-154.

15. Abena AA, Atipo-Ebata JK, Hondi AT, et al. Psychopharmacological properties of crude extract and essential oil of Lippia multiflora. Encephale. 2001;27(4):360-364.

16. Kumar P. Valuation of medicinal plants for pharmaceutical uses. Current Science, Review Articles. 2004;86(7):930-937.

17. Acquaye D, Smith M, Letchamo W, et al. Lippiatea centre for new use agriculture and natural products. New Brunswick, New Jersey, USA: Rutgers University; 2001. 
18. Asfaw Negesse. Determinants of smallholder farmers' commercialization of head cabbage (Case Study in Kofale District, West Arsi Zone, Oromia Regional State, Ethiopia). International Journal of Agriculture \& Agribusiness. 2018;1(1):74-85.

19. Tabachnick BG, Fidell LS. Using multivariate statistics. 5th ed. Boston: Pearson Education. Edition, Allen \& Unwin, Berkshire; 2007.

20. Mwangi JW. Pharmacognostical and biological studies of Kenyan Lippia species with special reference to their essential oil content. Ph.D thesis, Kenya: University of Nairobi; 1990.
21. Pallant J. SPSS survival manual: A step by step guide to data analysis using the SPSS program. 4th ed. 2011.

22. Adekunle MF, Agbaje BM. Public willingness to pay for ecosystem service functions of a peri-urban forest in Abeokuta, Ogun State, Nigeria. 2011 